Journal of Transdisciplinary studies

\section{ON INCLUSIVE LANGUAGE USAGE BY SPEAKERS OF ENGLISH AS A FOREIGN LANGUAGE}

\section{Nejla Kalajdžisalihović}

Abstract: The paper discusses language changes in contemporary English with regard to recently introduced inclusive expressions and challenges pertaining to activating their usage. The aim of the paper is to illustrate strategies that students use to activate inclusive language and politically correct vocabulary in English as a foreign language and to discuss whether the lexico-grammatical structures may reveal more about difficulties in activating inclusive vocabulary. For students of English as a foreign language, or even speakers whose L1 is English, what may cause certain problems in activating inclusive language is not only the question of being unsure about the correct expression but also being unsure about the syntactic and semantic structure of inclusive forms or expressions. In terms of the lexico-grammatical structures, it is proposed that inclusive language acquisition needs more attention in the future for speakers of English as a foreign language.

Keywords: inclusive language usage, politically correct language, contemporary English, vocabulary acquisition.

Nejla Kalajdžisalihović is Assistant Professor at the Department of English Language and Literature, Faculty of Philosophy, University of Sarajevo. She has delivered lectures abroad as a guest lecturer (Matej Bel University, University of Warsaw, University of Skopje) and in Bosnia-Herzegovina (Faculty of Traffic and Communications, University of Sarajevo and Faculty of Metallurgy and Technology, University of Zenica). Her scholarly research interests include psycholinguistics, contemporary English, English for aviation and forensic linguistics. E-mail: nejlak@gmail.com.

\section{Introduction}

The present paper is concerned with inclusive language usage in contemporary English as understanding how language changes as times change may be crucial for an academic or business setting. This topic can be studied from various points of view and using different theoretical frameworks. However, the focus of this paper casts light on some aspects of the usage of inclusive language by students whose L1 is not English. In order to address the issue of language production in relation to inclusive language and political correctness, the theoretical framework of the present paper will include references to Slobin's Language and thought online-Cognitive consequences of linguistic relativity (1987), Pinker's The stuff of thoughtlanguage as a window into human nature (2008), Burridge's Euphemism and language change-The sixth and seven ages (2012), and Teaching politically correct language (Tsehelska, 2006).

The research also revolves around the claim that cognition plays a dynamic role within the framework of linguistic expression as we are constantly involved in preparing, producing, and interpreting verbal messages (Slobin, 1987). In terms of language production, it is important to mention a quote by Burridge by which she concludes her research on euphemism and the word formation processes claiming that "modern speakers of English share with their ancestors a profound respect for the close relationship between word and meaning and this remains a powerful motive for language change" (Burridge, 2012, p. 89). For that reason and in terms of political correctness and inclusive language, it will also be observed how one fits one's thoughts into "available linguistic forms" (see Slobin, 2003; Traxler \& Gernsbacher, 2006). According to Slobin and in relation to linguistic expression, "a more codable expression is more accessible in psycholinguistic terms - that is, it is short, and/or high frequency, and generally part of a small set of options in a paradigm or small set of items" (Slobin, 2003, p. 435). In the case of inclusive language acquisition and activation, it is proposed in the present paper that, regardless of instruction or awareness about language change in terms of political correctness and inclusive vocabulary activation, students studying English as a foreign language will face difficulties with regard to activating inclusive pronouns, nouns and adjectives. 


\section{On Inclusive Language Usage — Theoretical Background}

In some cases, even speakers whose L1 is English, as previously mentioned, may be confused about a novel usage as is the case with the term cat's eyes, now replaced by road studs (Nsubuga, 2017). Also, the definition of euphemism as "the substitution of an agreeable or inoffensive expression for one that may offend or suggest something unpleasant" (Merriam-Webster, 2021) becomes problematic if learners of English do not recognize what may be offensive or what has become offensive recently. Furthermore, it should be mentioned that some attempts to apply inclusive language are considered unlikely to be accepted by speakers of English such as a replacement or change of the word genius, for instance, which is also listed among the words said to carry assumptions of gender inequality, class and ethnicity (see Sellgren, 2017). On the other hand, the word forefathers is likely to be semantically shifted to ancestors just like a snowman is likely to be semantically shifted to snowpal. This is, perhaps, not due to a lack of awareness pertaining to political correctness but due to a lack of an accessible linguistic form, a noun in this case. Of course, it would be impossible to list all the issues in the present paper as there are numerous examples and hot debates in newspaper articles and blogs on euphemism, language change and political correctness, among the most recent ones being related to gender-inclusive solutions pertaining to the nouns 'mother' and 'father' suggesting replacements such as 'gestational parent' and 'non-birthing parent' (see Mazzoni, 2021; Naumoska, 2010, p. 28). Nevertheless, the changing face of what is considered to be inclusive, or politically correct, presents a challenge in terms of how to assess linguistic content in terms of language production as the law of semantic change and Pinker's euphemism treadmill imply that, generally, euphemisms become tainted over time and that "negative associations reassert themselves to undermine the euphemistic quality of the word" (Allan, 2019, p. 189).

When it comes to inclusive language usage, there are several approaches which could be taken into consideration in order to relate language production to language acquisition with learners of English in mind. What is relevant for an academic or business setting and in relation to the previously mentioned newspaper articles related to inclusive language usage on the campus, for instance, is the emergence of the so-called codes of practice presented to university students in some countries, giving them clear guidelines on how to use the English language to avoid stereotyping, discrimination, making assumptions on ground of age, disability, gender reassignment, marriage and civil partnership, race, religion, or belief. For instance, Cardiff Metropolitan University Code of Practice on Using Inclusive Language (2017) raises awareness about the effects of potentially discriminatory vocabulary. Other similar examples may be found in the University of Warsaw Anti-Discrimination Guidebook for Students and Employees (2017).

Although codes of practice may be of relevance as a material for the acquisition of inclusive language and terminology, it could be discussed whether the production of unacceptable or ungrammatical solutions, in some cases, is also a result of the language acquisition process. In other words, students studying English as a foreign language, or studying in English, may unintentionally produce offensive or grammatically unacceptable forms due to a lack of knowledge with regard to inclusive vocabulary and inclusive syntactic forms in the process of FL production. Therefore, guides and manuals, such as the previously mentioned codes of practice, may also be used as materials for studying and analysing syntactic structures of the newly introduced forms and may as well be used as a material for translation classes.

\section{Research Framework and Methodology}

In order to assess how inclusive language production operates on a micro-level without labelling sentence elements as (politically) incorrect or lexical items as non-inclusive, an anonymous survey was conducted in April 2019 at the University of Sarajevo (Department of English Language and Literature, 25 participants) and the University of Warsaw (Institute of Applied Linguistics, 20 participants). A printed handout (see: Appendix 2) was distributed to students during the class in order to determine which linguistic strategies they use to change the sentences containing non-inclusive language as to make them more inclusive and as instructed in the handout. In total, 158 responses were collected and examples on how different parts of speech (pronouns, nouns, adjectives) were changed into more inclusive equivalents will be provided in the next section of the paper.

The task-oriented research was based on similar tasks (see Appendix 1, Task 1 and Task 4) by Thehelska (2006). The tasks were merged and adapted for the purpose of the present research and data collected will be analysed for sentences 1, 3, and 6 from Task 1. As for Task 4, data collected 
for paraphrases of sentences 2 and 7 will be also provided and analysed in further text. As for sentences 4 and 5 from Task 4, the handout distributed to both groups of students also included these two sentences, but they will not be analysed since the responses were either absent or stated that nothing should be paraphrased as the expressions are idiomatic.

The motivation for doing this research is found not only in the previously mentioned papers by linguists on language change, political correctness and activating available linguistic forms, but also in the fact that the author of the inclusive language exercises mentioned the relevance of the subject of inclusive language as one linking historical, cultural, social and linguistic issues. Since the article was published in 2006, the suggestions for the tasks provided (see Thehelska, 2006, Task 4 Key) shows how language changes in relation to the current usage and how the responses provided below may reflect such changes.

\section{Interpretation of Data}

For Example (1) - A teacher should be tolerant with his students, the following paraphrases (the number of responses is indicated in brackets) were collected:

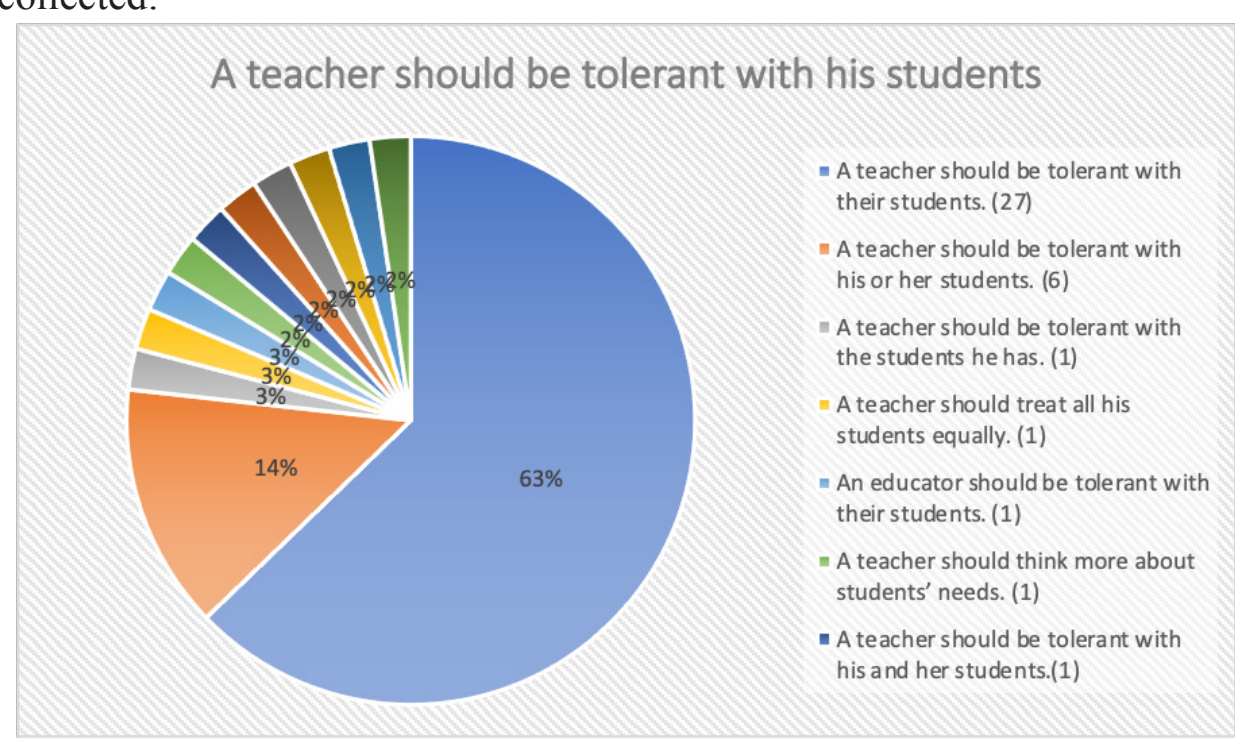

Fig. 1. Responses for Example (1)

As can be concluded for paraphrases provided for Example (1), the greatest number of responses (27) indicates that the pronoun 'his' was detected as the sentence element, i.e. pronoun, that needs to be replaced by 'their'. Other strategies were used as well, the second most frequent being a replacement of 'his' with a more inclusive equivalent 'his or her' or even 'his and her' (1). Still, a number of responses (4) did not focus on the personal possessive pronoun 'his' but on other sentence elements that did not require replacement in which case some ungrammatical solutions were also provided. In the greatest number of responses, the participants replaced one pronoun (in singular) by another pronoun (in plural)

For Example (2) - An actress is usually nervous before the show, students provided the following responses, whereas the responses are reproduced as given (i.e. where no full sentences were provided by the students):

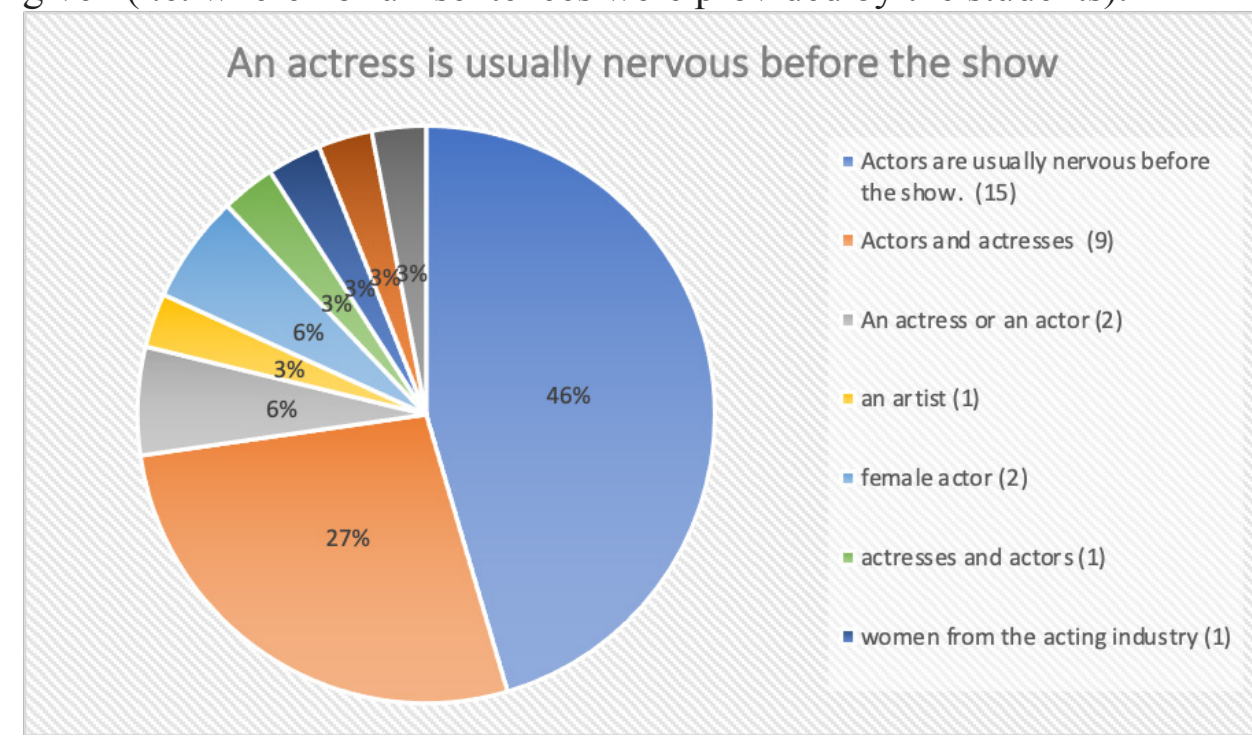

Fig. 2. Responses for Example (2)

As for paraphrases provided for Example (2), the greatest number of responses (15) indicates that the noun 'actress' was detected as the sentence element, i.e. the noun that needs to be replaced by another noun and was replaced by the word 'actor' in plural. Other strategies used included both nouns (i.e. actors and actresses) in 9 responses, which indicates that students do not find the word 'actress' carrying negative connotations or are not familiar with the questions raised on whether individual actresses prefer to be called 'actors'. Other responses, as can be seen from Fig. 2, show inconsistency or are not correct with regard to meaning. As for paraphrases provided for Example (3) - Man is destroying our planet, the word 
'man' was replaced by 'people' in 17 responses, followed by 'humans' and 'the humankind'. The responses also indicate that the learners are not sure whether a noun in singular or plural should be provided in the paraphrase.

In one response, the participant of the survey was, as it seems, more critical of the claim in the sentence to be paraphrased and provided a more empathetic response to indicate that it is not people who are destroying our planet but their actions (see Fig. 3):

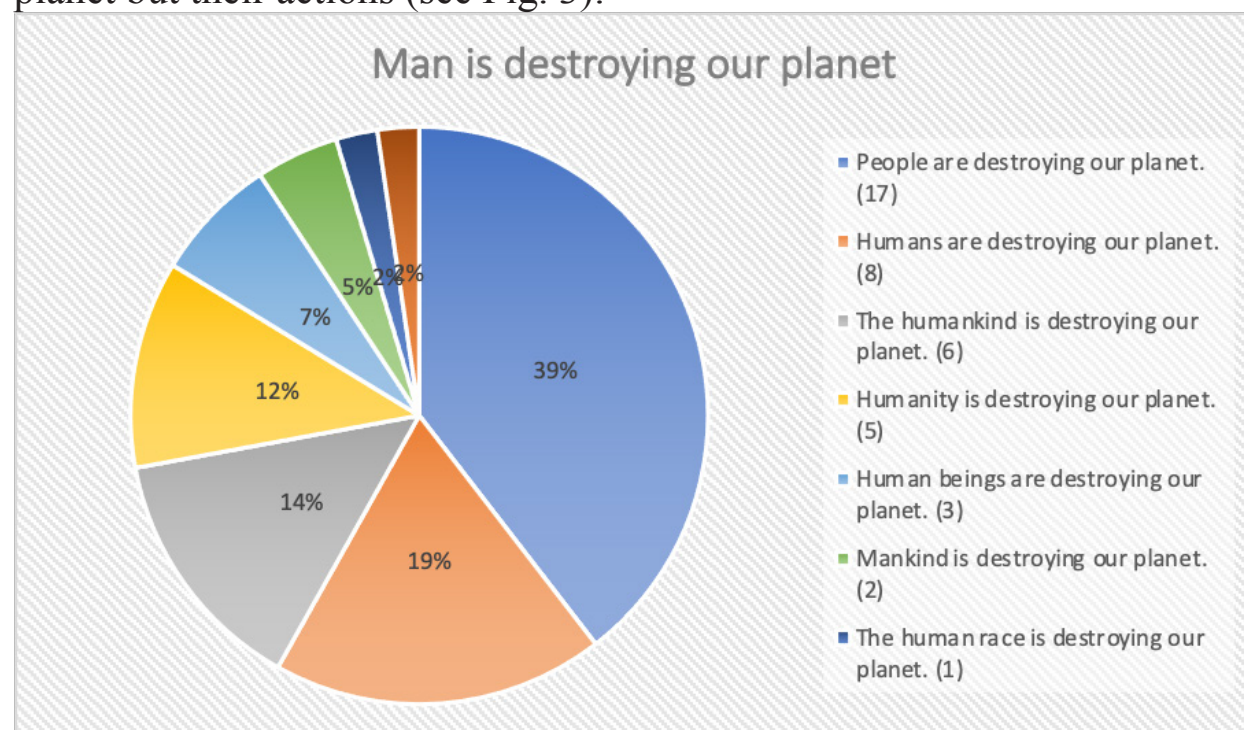

Fig. 3. Responses for Example (3)

Interestingly, the greatest number of different responses was collected for the following sentence: (4) Fat people need to go on diets, as can be observed from the examples provided below (See Fig. 4). In terms of the available linguistic forms and strategies, the greatest tendency to shift towards a 'people first' approach on the sentence level was found in Example (4). At the same time, the number of numerous and varied responses may indicate that learners are not confident about activating inclusive nouns and pronouns in English as a foreign language as well as that there may be external and culturally-embedded factors involved (e.g. whether 'obese' and 'overweight' are perceived as offensive words).

The answers provided are also in line with the suggestions by Thehels$\mathrm{ka}$ in 2006 (8 responses), but attempts to opt for a 'people first' approach are clearly seen from Fig. 4 ('people with obesity', 'people who are over- weight', 'people who struggle with weight', 'people with an unhealthy body mass index', etc.).

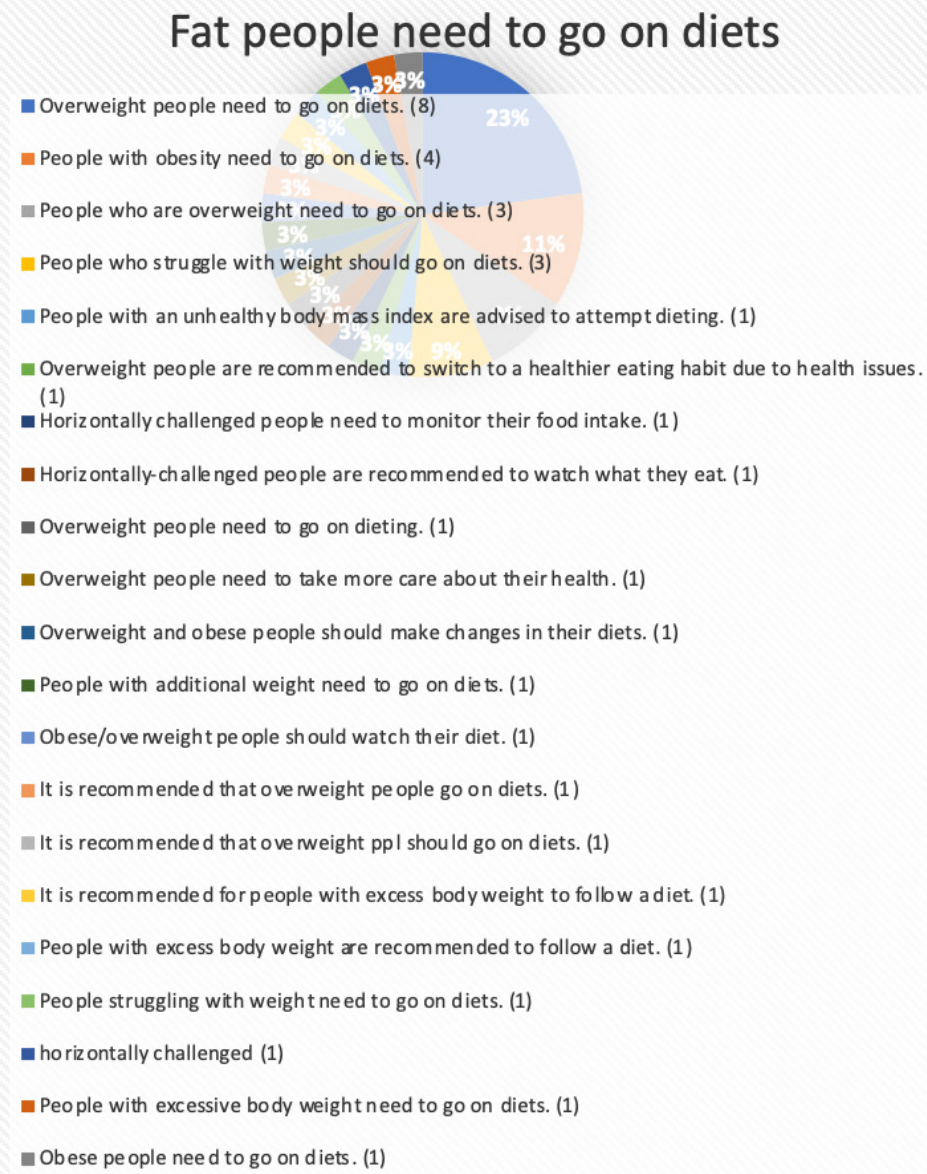

Fat people need to go on diets

- Overweight people are re commended to switch to a healthier eating habit due to health issues.

(1)
- Horiz ontally challenged people need to monitor their food intake. (1)

- Horizontally-challenged people are recommended to watch what they eat. (1)

- Overweight people need to go on dieting. (1)

Overweight people need to take more care about theirhealth. (1)

- Overweight and obese people should make changes in their diets. (1)

- People with additional weight need to go on diets. (1)

- Obese/ove weight pe ople sh ould watch their diet. (1)

- It is recommended that ove weight pe ople go on diets. (1)

-It is recommended that ove weight ppl should go on diets. (1)

It is recommended for people with excess body weight to follow a diet (1)

- People with excess body weight re recommended to follow a diet. (1)

- People struggling with weight need to go on diets. (1)

- horizontally challenged (1)

- People with excessive body weight need to go on diets. (1)

n- Obese pe ople need to go on diets. (1)

Fig. 4. Responses for Example (4)

Therefore, in the case of Example (4), as can be seen from the responses above, the participants activated inclusive or non-discriminatory language in a similar people-first manner (see PFL, Using Inclusive LanguageGuidelines and Examples, 2020). Although Slobin, when referring to "readily encodable in language", refers to closed-class grammatical morphemes, tense/aspect inflections, particles and prepositions (adjectives excluded), Example (4) could mean that more attention needs to be given to understanding patterns of inclusive language in FL/L2 (or the lack thereof) or perhaps ways how exposure to social networks affects language usage. 
In addition, different linguistic strategies were also detected in examples on illness and old age, as can be seen from the responses below. As for 'the elderly', the responses provided show that the students usually opted for a less acceptable form from the one provided in the original and there were no responses that would use different and more recently introduced phrases such as 'senior citizens' (see Thehelska, 2006, Task 4 Key) or 'people aged'. However, it is interesting that the word 'people' occurs in almost all of the responses, which is why it can be claimed that the people-first approach was observed in Example (5) as well (see Fig. 5).

It is also necessary to mention is that all of the examples collected have not been produced through spontaneous language production and were obtained by means of task-based instruction and submitted in the written form. There is, of course, a possibility that language production, or even comprehension, in a different, more spontaneous spoken or written language activation and usage would have yielded different responses.

In terms of translation-based tasks, another activity that could contribute to results when it comes to activating inclusive vocabulary (especially nouns, pronouns and adjectives) could rely on asking students to provide translation equivalents from English into their L1. In that way, a comparison could be made between different language pairs to see if these categories present a problem in speakers' L1, as well as there are different inclusive expressions used that students may not be aware of or may not be using in their everyday written/spoken communication or academic writing.
The program offers long-term care for the elderly and immediate care for the mentally retarded.

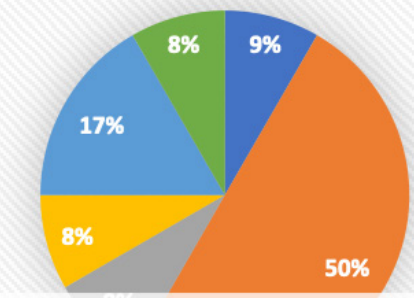

- The progr am offers long-ter $m$ care for older people and immediate care for people with mental dispairment. (1)

The program offers long-ter $m$ care for older people and immediate care for people with mental disabilities. (6)

The program offers long-ter $m$ care for the elderly and immediate care for the people with intellectual disability. (1)

- The program offers Iong-ter $m$ care for older people/pensioners and immediate care for the people with mental disabilities. (1)

The program offers long-ter $m$ care for older people and immediate care for the people with intellectual disabilities. (2)

- The program offers long-ter $m$ care for older people and immediate care for the mentally disabled. (1)

Fig. 5. Responses for Example (5)

Furthermore, what could also be tentatively concluded from the responses is that, in the case of pronouns and nouns, L1 could also be contributing to a lack of a ready-to-be-activated linguistic form. In the case of vulnerable categories, such as illness or old age, the responses for Example (5) show that there is a variety of responses, some of which are less acceptable when compared to the category of weight and physical appearance for which more types of responses were given. In order to assess what factors motivate correct or more frequent inclusive language solutions, regardless of one's L1, more extensive research needs to be done in the future using more examples or focusing on one part of speech only (adjectives, for instance). 


\section{Conclusion}

In the present paper, task-based research on the usage of inclusive language conducted in 2019 at the University of Warsaw and the University of Sarajevo was presented to discuss how language changes in contemporary English affect inclusive language usage (especially when it comes to the activation of pronouns, nouns and adjectives) and how these changes may affect both inclusive language acquisition and production for learners of English as a foreign language or students studying in English. The material collected on the usage of recently-introduced inclusive language expressions was assessed for linguistic forms and their frequency for five sentences (see Tsehelska, 2006). In total 158 responses to five sentences were collected and analysed for the linguistic strategies used by 45 participants. It could be understood from the examples provided above that the students of English as a foreign language / students studying in English as a foreign language who completed the task are unsure about the usage of language that is considered inclusive, especially when it comes to gender-neutral inclusive language in contemporary English, as well as whether to use adjectives before the noun, in a relative clause, or in a prepositional phrase. However, based on the responses collected for the purpose of the present paper, it may be said that adjectives present a lesser challenge in terms of inclusive language usage than nouns or pronouns and that the people-first approach is generally observed.

The paper also suggests that learners of English as a foreign language / students studying in English as a foreign language are struggling when choosing the correct inclusive language equivalent, aside from ungrammatical responses. As a solution, codes of practice and inclusive language manuals may be used to assist the learners in the process, as well as translation-based tasks. Furthermore, texts that discuss ageing, illness and disease, occupations, and other relevant topics may significantly contribute to a more insightful inclusive language acquisition.

\section{APPENDIX 1}

Task 1

The following phrases use sexist language. Rewrite them to make them inclusive.

1. A teacher should be tolerant with his students

2. A child needs the love of his parents.

3. An actress is usually nervous before the show.

4. Mary is a camerawoman.

5. The committee elected a chairman.

6. Man is destroying our planet.

7. Today man-made fibers are used for manufacturing stockings.

8. This substance is not known to man.

Task 4

Many people are sensitive about their abilities, age, culture, and appearance. Make the following phrases sound inoffensive to the persons being spoken about.

1. She is looking after her insane mother.

2. The program offers long-term care for the elderly and immediate care for the mentally retarded.

3. A new clinic for the care of geriatrics is being proposed.

4. He is as blind as a bat.

5. My neighbor is as deaf as a post.

6. Jane is an emotional cripple.

7. Fat people need to go on diets. 


\section{APPENDIX 2}

\section{Rewrite the following sentences to make them inclusive:}

1. A teacher should be tolerant with his students.

2. An actress is usually nervous before the show.

3. Man is destroying our planet.

4. The program offers long-term care for the elderly and immediate care

for the mentally retarded.

5. He is as blind as a bat.

6. My neighbor is as deaf as a post.

7. Fat people need to go on diets.

\section{References}

Allan, K. (2019). The Oxford handbook of taboo words and language. Oxford: Oxford University Press.

Burridge, K. (2012). Euphemism and language change: The sixth and seventh ages. Lexis, (7), 65-92.

Cardiff Metropolitan University - Study in Cardiff. (n.d.). Retrieved from https://www. cardiffmet.ac.uk/about/structureandgovernance/documents/code $\% 20$ of $\% 20$ practice $\% 20$ and $\% 20$ guide $\% 20$ to $\% 20$ inclusive_language_2013.doc

Euphemism. (n.d.). Meriam Webster Dictionary. Retrieved from https://www.merriam-webster.com/dictionary/euphemism.

Inclusive Language Guide: Definition \& Examples. (2020, January 23). Retrieved from https://online.rider.edu/online-bachelors-degrees/liberal-studies/guide-to-using-inclusive-language/

Kedziora, K., \& Gredzinska, A. (2017). We Are All Equal-Anti-Discrimination Guidebook for Students and Employees of the University of Warsaw. Warsaw: Warsaw University Press.

Mazzoni, A. (2021, February 15). Academics from nation's top university tell staff to call mothers the 'gestational parent' and fathers the 'non-birthing parent' - and there is even a gender-neutral term for breastfeeding". Retrieved from https://www.dailymail.co.uk/ news/article-9262007/Academics-Australian-National-University-told-staff-stop-using-word-mother.html

Naumoska, A. (2010). Родовата обележсаност во англискиот јазик. Skopje: Vinsent Grafika.

Nsubuga, J. (2017, August 14). Council renames 'cats eyes' after American tourists thought they were made from real cats. Retrieved from https://metro.co.uk/2017/08/14/council-renames-cats-eyes-after-american-tourists-think-animals-are-being-hurt-6851958/?ito=cbshar.

Pinker, S. (2008). The stuff of thought: Language as a window into human nature. London: Penguin Books.

Sellgren, K. (2017, June 13). Term genius alienates women, says Cambridge lecturer. BBC News. Retrieved from https://www.bbc.com/news/education-40259449 
Slobin, D. I. (2003). Language and thought online: Cognitive consequences of linguistic relativity. In D. Gentner \& S. Goldin-Meadow (Eds.), Language in mind: Advances in the investigation of language and thought. Cambridge, MA: MIT Press, 157-191.

Traxler, M. J., \& Gernsbacher, M. A. (2006). Handbook of psycholinguistics. Boston: Elsevier.

Tsehelska, M. (2006). Teaching politically correct language. English Teaching Forum, pp. 20-32. Retrieved from https://files.eric.ed.gov/fulltext/EJ1107901.pdf 